\title{
THE ELEMENTS OF INTERACTIVE FICTION IN "PROMINENCE"
}

\author{
Nur Aizzat Izzaty Abdul Rahim ${ }^{1}$ \\ School of Humanities, Universiti Sains Malaysia (USM), Malaysia \\ (Email: nuraizzatizzatyabdulrahim@gmail.com) \\ Dr. Halimah Mohamed Ali ${ }^{2}$ \\ School of Humanities, Universiti Sains Malaysia (USM), Malaysia \\ (Email: halimah@usm.my) \\ Professor Dato' Dr. Sohaimi Abdul Aziz ${ }^{3}$ \\ School of Humanities, Universiti Sains Malaysia (USM), Malaysia \\ (Email: soaazz@usm.my)
}

Accepted date: 16-03-2019

Published date: 10-07-2019

To cite this document: Rahim, N. A. I. A., Ali, H. M., \& Aziz, S. A. (2019). The Elements of Interactive Fiction in "Prominence". International Journal of Heritage, Art and Multimedia, 2(5), 16-33.

DOI: $10.35631 /$ ijham. 25002

\begin{abstract}
Prominence" is a new adventure computer game. It is also new as a genre of interactive fiction in the corpus of electronic literature. Hence, the study of "Prominence" in the context of interactive fiction genre is also a study that has not been carried out yet exclusively in the aspect of its structure. For that reason, this paper aims to primarily focus on the structure of "Prominence". Mainly, the structural elements of interactive fiction in "Prominence" that will be discussed are pronged by four elements; a computer program, potential narrative, world model and game. By focusing on the four main structural elements, this paper shows how "Prominence" works as an interactive fiction. The interactor's interactivity with all these four elements of interactive fiction in playing, engaging and navigating discourse would likely give a diverse sense of aesthetic experience while interacting with the play, which is called immersive pleasure. The discussion on these elements of interactive fiction supports the interactor to successively challenge their self to fit into the play and draw inference on new ideas and information they find during interaction.
\end{abstract}

Keywords: Interactive Fiction, Structural Elements, Montfort, Game

\section{Introduction}

After the debut of interactive fiction in the late 20th centuries, conventional readers are also seemingly seen as the potential interactors in interactive fiction. In view of the fact that they can use a wide array of technology at their fingertips, for instances, navigating, seeing images, watching videos, and hearing sounds and special effects that are inserted in the gaps of every narration, similarly as gamers. In addition, this type of narratives provides a huge amount of hypertexts that serve as a tool to expand the story lines. Therefore, interactive 
fiction, also called IF, allows interactor to enjoy the opportunity to experience the acts of engaging and immersing, in which conventional readers cannot experience in the printed novels. Presently, writers and designers of interactive fiction have vigorously created narratives that combine all the elements of media convergence in order for the interactor to achieve the fullest pleasure in enjoying interactive fiction as new media. As an example of the latest interactive fiction is "Prominence". Since the full project launched in 2015, it is predicted to comprise the latest invention of digital technology.

"Prominence" has become one significant example of a comprehensive interactive fiction because it has what it takes to be an interactive fiction; story and game. That is why "Prominence" is considered as a new kind of storytelling in electronic literature world. "Prominence" started as a computer game invented by Mike Morrison and his team, Digital Media Workshop. But this kind of game has a lot more to offer than just a game-play. Its digital form has smartly expressed its new narrative form in the promising way. The interactor will realize some new features added to "Prominence" as compared to other interactive fiction in which sophisticated and highly digitalized. Perhaps, this will lead the interactor to completely absorb in engaging and interacting with "Prominence". For the interactor to be immersed when interacting with any kind of interactive fiction, an ability to closely engage with the work is indispensable. Thus, more engagements will produce more interactions. Therefore, this has driven a motivation and desire for this paper to analyse the nature of "Prominence".

\section{Theory}

\section{Nick Montfort}

The phrase "interactive fiction" (or so-called IF) is first used in the area of Infocom's marketing in the early 1980s (Plotkin \& Kudla, 2011, 66) and often referred to digital versions of literary works in which the interactor uses text commands to control player characters and influence the simulated environment. Interactive fiction is also often understood as a form of video game or text adventure because of the way to interact with the play is by typing text and pointing-and-clicking. Henceforth, when going through researchers' works, IF is often found and widely used as a short form to refer to the interactive fiction and its related literary works.

Nick Montfort's theory of interactive fiction will be applied in the study, given the importance of perception in analysing immersive pleasure, even though the theory is still developing. In this theory, Montfort (2003) tries "to build a theory of interactive fiction that is useful in deeply understanding how interactive fiction is experienced, and how better sorts of works can be created." This meshes well with the offerings of "Prominence", which fall into the interactive fiction category. "Prominence" claims in its mission statement that it wants to sell not only a product (software), but also a feeling; therefore, the interactor's involvement in interacting with "Prominence" cannot be taken lightly. It should be studied seriously because it will play an important role. Thus, in order to analyse how the immersive pleasure which derived from the interactor's interactivity works in "Prominence", the theory of Montfort is therefore more relevant to the study.

Indeed, the theory of interactive fiction by Nick Montfort is applied in the study. In his first book Twisty Little Passages (2003) on the discussions of interactive fiction, Montfort originally defined that interactive fiction includes the necessity of a computer. It is still possible to develop interactive fiction for use without a computer. Such an example would be 
the "Choose Your Own Ending" series of handheld books. Montfort (2011) further described interactive fiction as "a category that is typically represented by the text adventure or text game, has literary, gaming, and other important aspects". Even so, interactive fiction is not a completely new paradigm. There are some debates touched on the significant aspects of interactive fiction, but there is no theory that has been developed exclusively on interactive fiction. Even though the theory is still developing, Montfort (2003) tries to construct a theory of interactive fiction that can benefit interactive fiction community in order to gain better understandings on "how interactive fiction is experienced", and "how better sorts of works can be created".

Approximately, this is a working definition of interactive fiction by Montfort, "a game that is controlled by textual input, understood as its natural-language meaning (to some degree), and that provides a simulated game world, which behaves according to natural rules (to some degree)" (Plotkin \& Kudla, 2011, 62). Based on Montfort's theory, the nature of interactive fiction consists of a "computer program" that has "potential narratives" in the virtual "world" and also a part of "game" which then referring to the structure of interactive fiction in the play. Montfort somehow did not include "interactor" as one of the principles of interactive fiction. This is because the function of an "interactor" represents in every principle to develop the process of exploration or engagement in the play. The word "interactor" is first created by Montfort to replace "player" in the interactive fiction since the term "interactor" shows a better meaning of an individual who interacts with the interactive fiction works. Whereas, the term "player" has other meaning associated to an individual who plays games. Therefore in this study, the term "interactor" will be used instead of "player" during the course of the analysis.

As a matter of fact, Montfort assured that the principles of interactive fiction have an impact on the interactor's immersive pleasure. In his theory, Montfort (2003) shows that interactive fiction has its own basic principles in terms of "program" which is referred to a text accepting and text-generating computer program, "potential narratives" that is, a system which produces narrative during interaction, "world model" which is a simulation of an environment or world, and "game" that is a structure of rules within which an outcome is sought (p. 2). These principles are identified to explain how the structure of interactive fiction works with the interactor. First and foremost, interactive fiction is recognized as a text accepting and text generating computer program because interactive fiction is a computer program that receives commands from the interactor and produces responses from the play or the player's character. Here, interactivity occurs between both parties. Additionally, interactive fiction features two distinct modes of writing; the player input and the game output (Montfort, 2003, 3). Therefore, interactive fiction understands natural language to an extent and replies to this input in a meaningful way (output). Secondly, interactive fiction produces potential narrative during interaction between the interactor and the play. Potential narrative could only exist when the interactor and the play interact. As a form of new media, it allows for the discovery of new texts upon repetition with different explorations.

Thirdly, interactive fiction also consists of "world model" which is a simulated environment of virtual world, which can be explored and interacted with, and the interactor's actions bring an immediate effect to the world. This simulated environment of virtual reality has also been called "rooms", "locations" or "areas" depending on the types of places the interactor enters (Montfort, 2003, 11). This third principle is also the highly influential part where immersive pleasure is found within the interactor of interactive fiction. Fourthly, interactive fiction is identified as a game, meaning that it has a specific goal, and certain rules which must be 
followed and is played voluntarily in order to reach the outcomes. The rules are either to be followed or meant to be broken. Therefore, the outcomes may vary either be positive or negative. Interactive fiction at its best is both a rewarding "reading" experience and a challenging game.

\section{Analysis}

Further, this paper will discuss on the four elements of interactive fiction in "Prominence" lay out by Montfort. As discussed above, by using Montfort's theory of interactive fiction, there are four elements of the structure of interactive fiction. The central elements of the structure of interactive fiction are listed as follows:

— text-accepting, text-generating computer program;

— simulation of an environment or world model;

- potential narrative; and

- game

The interactor's interactivity with all these four elements of interactive fiction in playing, engaging and navigating discourse would give a diverse sense of aesthetic experience while interacting with the play, which is called immersive pleasure. This discussion about these four elements of interactive fiction helps the interactor to subsequently challenge their self to fit into the play and interpret new ideas and information they find during interaction.

Certain elements are used in an excessive way; more or less, in all variation of interactive fictions. Mike Morrison and his team have produced a complex, highly advanced program (software) but accessible version of interactive fiction of "Prominence", to promote interactor's aesthetic experience in a very different way than other kinds of interactive fiction. Instead, the team sometimes puts a specific overt dimension to upraise interactor's interactivity and test their senses of engagement and immersion as well while playing "Prominence". This chapter will describe how the interactor's perspectives while interacting in the play can be differentiated from what is computed and displayed by the program (Montfort, 2003, 24). Therefore, the four elements would prove that "Prominence" is not only a computer game; it is more of an interactive fiction. Further, the following elements of interactive fiction are used to discuss interactor's aesthetic experiences and interpretations during interaction.

\section{Text-Accepting, Text-Generating Computer Program}

First and foremost, "Prominence" is recognized as a text accepting and text generating computer program. This means that "Prominence" produces text-based communication between interactor and the play. As in "Prominence", Montfort elaborated that text accepting is referred to as the play accepts textual responses produce by interactor while interacting with the play. Whereas, text generating means the play displays additional text in reaction to what has been typed by interactor. Here, there is interactivity occurred between both parties. "Prominence" produces a text-based hacking system where interactor communicates with the portable computer by using text-based communication in order to find location, or to know the method to activate power, or even to gain information about certain room.

There are two types of generated texts in "Prominence"; descriptive text and command text. The first type which is generating descriptive text allows interactor to obtain some information about the past events and people that had happened to the place or area the interactor currently interfaces. Obviously, the main computer system placed in front of the next room consists of some descriptions about the next task interactor has to complete. If 
interactor requests the details from the main computer, they would respond by text-based behaviour. Generally, the text produced by interactor is short and simple because interactor intends to seek for answers. Meanwhile, the text produced by the play is frequently in a long description and full of details because the play tries to give as much information as they could.

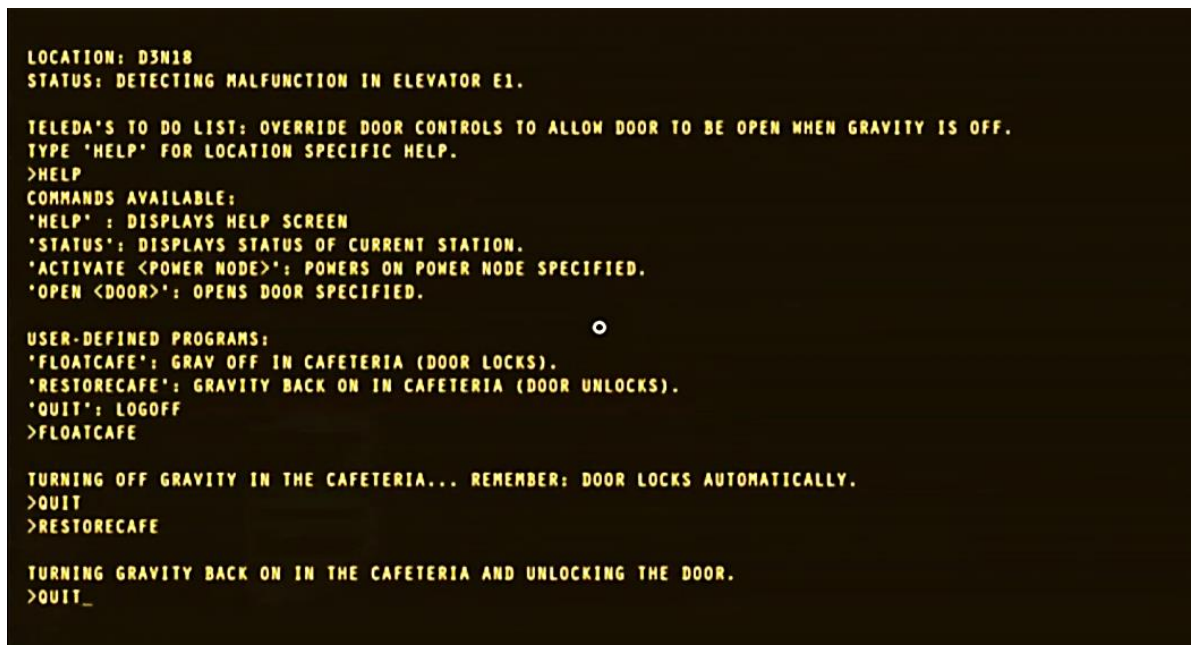

Figure 1: Generating Command Text

Between the two types of generated texts, generating command text is the most widely used in "Prominence", for instance as shown in Figure 1. As in "Prominence", much of the pleasure comes from the sense of exploring, going deeper and deeper into the spaceship and discovering unexpected passages. Interactor often confronts with the malfunctioned doors, elevators and power supplies. Thus, in order to solve the problems the interactor needs to communicate through the portable computer they have in the inventory to find for solutions. The interactor's useful generating command text generally consists of contributions such as help, activate, deactivate, open, close, quit, or restore. But such texts are actually understood within the specific domain of the interactive fiction world, by the work's parser. The interactor can use such commands only to control a particular action for certain time, as in to manually open a malfunctioned door or activate an elevator. Therefore, they are then translated into action by the interactor.

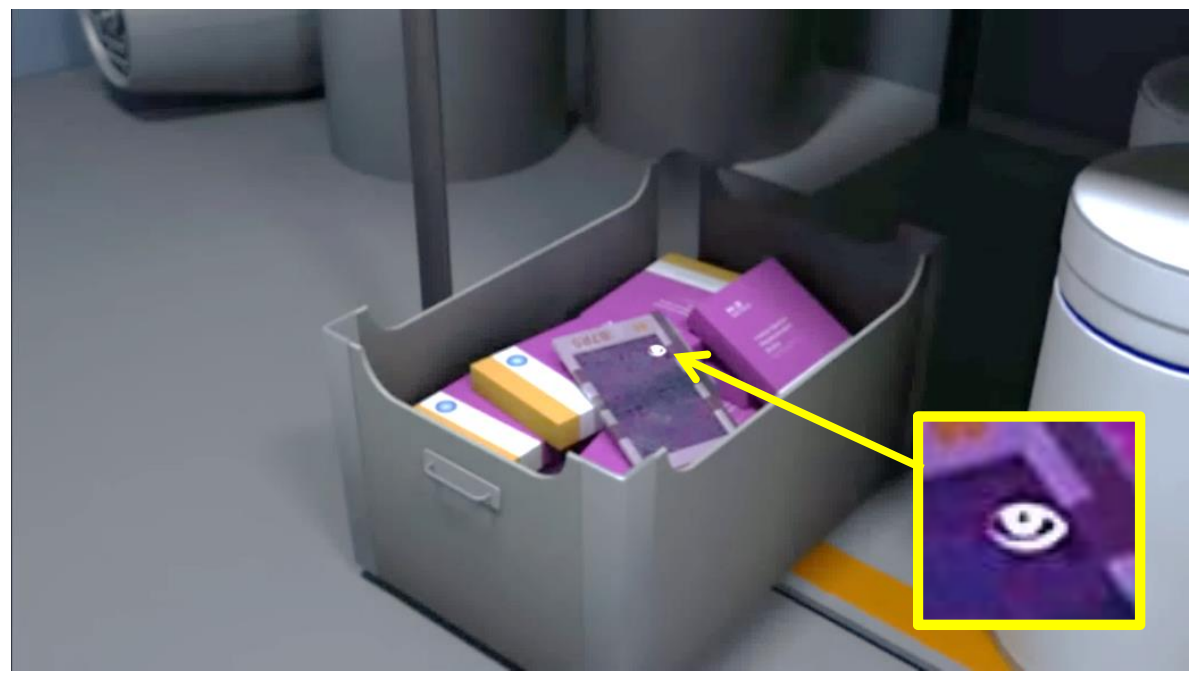

Figure 2: Zooming Out The Symbol Of 'Eye' Sign Detects A Notable Detail or Magnifier 
For basic navigation in "Prominence", the interactor moves the mouse to look around and the cursor would change whenever there is some interactions involved, for example as illustrated in Figure 2, the cursor will change into an eye whenever there is some notable detail or magnifier when there is an opportunity to zoom in and take a closer look, the cursor will change into a hand when there is an action that can be performed, and it also turns into an arrow when the interactor can move in a particular direction. This kind of text generating system controls the interactor's action by minimizing the interactor's options that could be used in each task which needs to be completed. It also helps giving some clues to the interactor of what they actually need to do. Thus, the interactor will never get stuck in a particular room with no progressing. This basic navigation is one of the ways to interact between the interactor and the play. In addition, the interactor also obtains information through cameras (CCTV) and computers. Those provide their own backstories about a particular location or event. Information that is saved in the CCTV used voices as the interaction between the interactor and the play. This kind of accepting text control system helps the interactor to gain better understandings about the situation they confront with. The collected information would be stored in the inventory together with all the emails and voicemails the interactor receives and could be used by the interactor to unfold other mysteries.

Generally, this play features two distinct modes of text writing; input which produces by the interactor and output which produces by the play (Montfort, 2003, 3). Therefore, interactive fiction understands natural language to an extent and replies to this input in a meaningful way (output). In brief, Montfort has come up with the best description of what is input and output. Based on Montfort's analysis, input is anything the interactor contributed. As example as when the interactor pressing the space bar to typing a long text. Whilst output is any text produced by the program even if this includes things previously typed by the interactor (Montfort, 2003, 25).

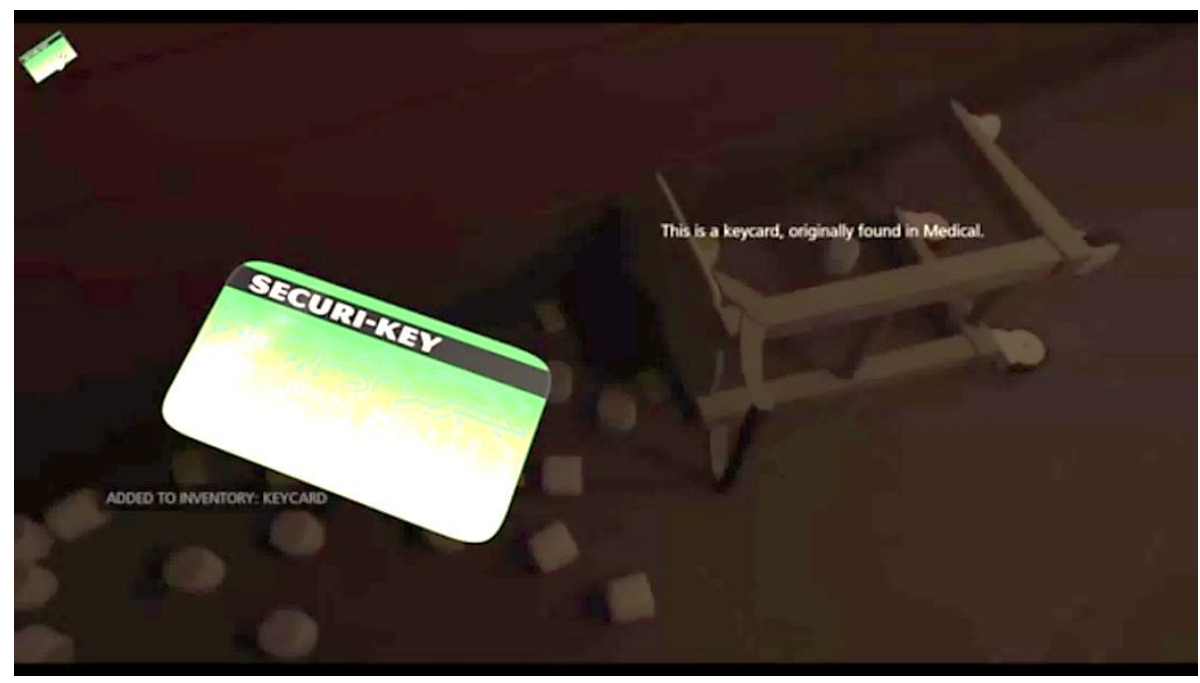

Figure 3: Zooming Out In-Game Footage of A Scene Where Interactor Picks Up The Key Card (Input) and The Play Adds the Key Card to The Inventory (Output)

Figure 3 shows that an output has appeared on the screen to deliver a new message for the interactor's information. For instance, a message sayings "ADDED TO INVENTORY: KEYCARD" appears as soon as the interactor picks up the key card on the floor. The message acts as an output to the interactor as a reply to the interactor's action of picking the 
key card up. Moreover, the output would include additional information about its function for each collected item. Thus, the interactor would use the information later in the next stage of interactivity. This sort of output would come out on the screen for multiple of times whenever the interactor picks an item from a particular place.

Therefore, "Prominence" is considered as a text accepting and text generating computer program because of the levels of accomplishment of the text-accepting produced by the interactor and text-generating produced by the play while interacting to each other, and the examples is shown in Table 1 below. The more the interactor interacts with the play, the more the levels of accomplishment increased. As compared to fictional story in the printed form, there is no input involved during the reading because only the story gives output to the readers, since readers use their imagination and logical sense to arrange the story in chronology. "Prominence" seems to be a new kind of story telling that uses computer and other digital devices as a different platform to experience the pleasure of immersion by playing "Prominence".

Table 1: Levels Of Accomplishment and the Examples of The Text-Accepting and TextGenerating Computer Program in "Prominence"

\begin{tabular}{|c|c|c|}
\hline $\begin{array}{c}\text { Levels of } \\
\text { Accomplishment }\end{array}$ & Text-accepting & Text-generating \\
\hline $\begin{array}{l}\text { Level } 1 \\
\text { (Novice-Curiosity) }\end{array}$ & Novice collects key card & $\begin{array}{l}\text { Key card is added in the } \\
\text { inventory }\end{array}$ \\
\hline $\begin{array}{l}\text { Level } 2 \\
\text { (Advanced beginner- } \\
\text { Sympathy) }\end{array}$ & $\begin{array}{l}\text { The advanced beginner } \\
\text { reactivates A.N.N.I.E }\end{array}$ & $\begin{array}{l}\text { A.N.N.I.E } \\
\text { information of the condition } \\
\text { of a particular room or } \\
\text { situation }\end{array}$ \\
\hline $\begin{array}{l}\text { Level } 3 \\
\text { (Competent- } \\
\text { Identification) }\end{array}$ & $\begin{array}{l}\text { The competent finds } \\
\text { schematic to fix A.N.N.I.E }\end{array}$ & $\begin{array}{l}\text { A.N.N.I.E gives order to } \\
\text { search for schematic }\end{array}$ \\
\hline $\begin{array}{l}\text { Level } 4 \\
\text { (Proficient-Empathy) }\end{array}$ & $\begin{array}{l}\text { The proficient accepts a } \\
\text { termination of contact from } \\
\text { A.N.N.I.E }\end{array}$ & $\begin{array}{l}\text { A.N.N.I.E realizes the truth } \\
\text { and comes back online }\end{array}$ \\
\hline $\begin{array}{l}\text { Level } 5 \\
\text { (Expert-Intimacy) }\end{array}$ & $\begin{array}{l}\text { The expert sacrifices his } \\
\text { safety by floating to the } \\
\text { damaged research room to } \\
\text { take navigation module }\end{array}$ & $\begin{array}{l}\text { A.N.N.I.E directs the expert's } \\
\text { way and clears his vision } \\
\text { from debris }\end{array}$ \\
\hline
\end{tabular}

\section{Simulation of an Environment or World Model}

Secondly, interactive fiction also consists of a simulated environment of world, which is also called "world model". The analysis in this chapter will not follow Montfort's order of the elements of the structure of interactive fiction; text-accepting and text-generating computer program, potential narrative, simulation of an environment or world model, and game. But the analysis will put simulation of an environment or world model as the second elements come after the first element of structure. This is because potential narrative could only be occurred in the virtual world. Therefore, the simulation of an environment of the virtual world should be discussed second before the discussion on potential narrative is elaborated.

The world model of "Prominence" can be explored and interacted with, and the interactor's actions bring an immediate effect on that world. This kind of world is considered virtual 
reality in nature. This simulated environment of virtual reality has also been called "rooms", "locations" or "areas" (Montfort, 2003, 11). Instead, this third element is also the highly influential part where immersive pleasure is found within the interactor of interactive fiction. As regard to Montfort's explanation on the third element, this three dimensional world model in "Prominence" is "no less than the content plane of interactive fiction, just as story is the content plane of a narrative" (Montfort, 2003, 26). In brief, interactive fiction world is a reflection of the real-life world the interactor live in, that is created in order to make them "absorbed" and being "immersed" in the world until they believe they really live the world literally.

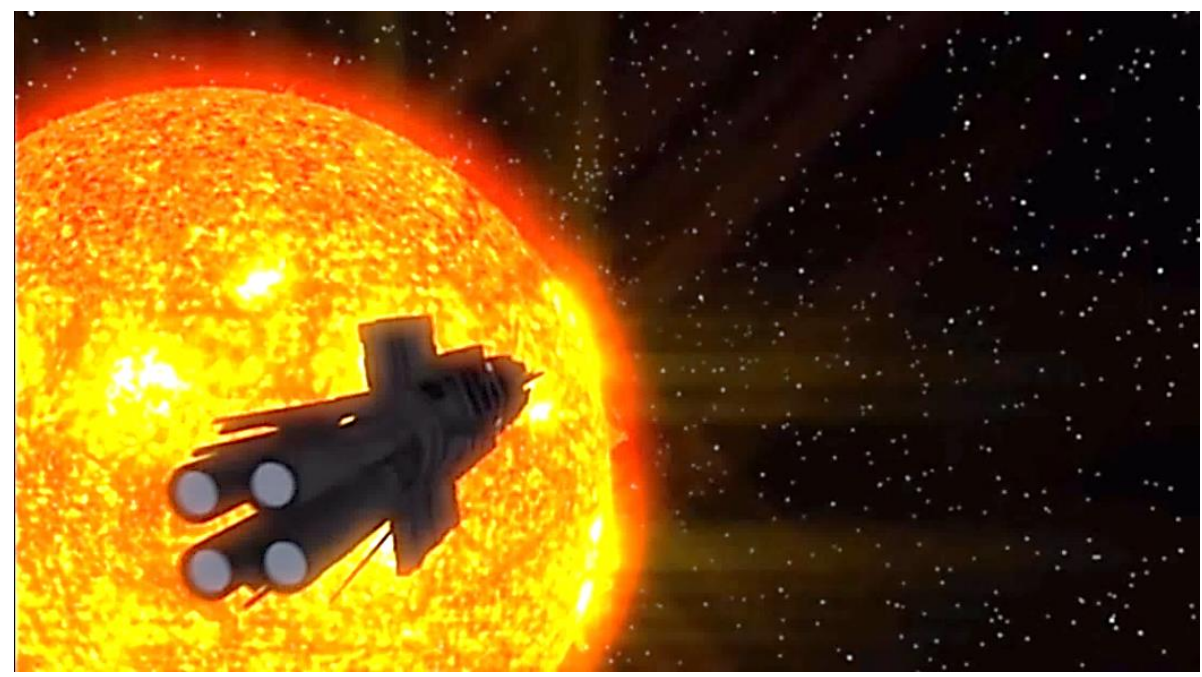

Figure 4: A Screen Shot of The Location of Vanguard Ship Which is Not Far from the Solar Prominence

Basically, "Prominence" simulates make-believe situation of real-life event in the space, as illustrated in Figure 4, where there is one world that is a huge spaceship named the Vanguard Ship, with a team of 30 experts. In the play, the location of the spaceship is shown not far from the solar prominence that has created explosion and severe damage to the ship. In due course, the fire that is looping hundreds of thousands of miles into space as a result from the solar prominence eruption has created debris which could destroy if not all, a part of the ship. After all, this is the main reason the ship cannot function well as before.

When moving around, point and click adventures like "Prominence" will often have the interactor jump from location to location so that interactor could walk into the world and see the transition from one location to the next. The influence of colours also appeared here. In the context of psychology, brighter colours represent positive mood. This fact is useful and accurate because throughout the mission the interactor would find that he has escaped the negative side of bad feelings such as frustration and deadlocked when entering the rooms and even when passing by the three junctions. The rooms and pathways are illustrated in brighter colours and objects are seen clearly than previous stages. This sudden change of colours also represents the interactor's enhancement in behavioural skills. Thus, without a doubt, the interactor's performance would improve and the potentials of hardships in the interactivity are getting smaller.

The spaceship consists of four main floors from which the interactor starts his mission on the second bottom floor which is the second level to escape to the bottommost level which is the hangar where the shuttle ship would fly back to the new residence. Each floor then consists of 
at least two to three different rooms that are locked where interactor needs to break the rooms by any methods to escape to the next room until they can reach the next floor. This sort of situation happens in "Prominence", which really helps create the sense of scale and minimizes the chance of getting lost and confuse as interactor explores the simulated world. "Prominence" also builds in the ability to override this transition, where interactor can do that in the option menu or simply holding the control key while clicking to move so interactor does not have to sit through them if interactor does not want to or if interactor becomes comfortable with the particular location. The transition of rooms in the spaceship and the change of colours are shown in the following Figure 5.

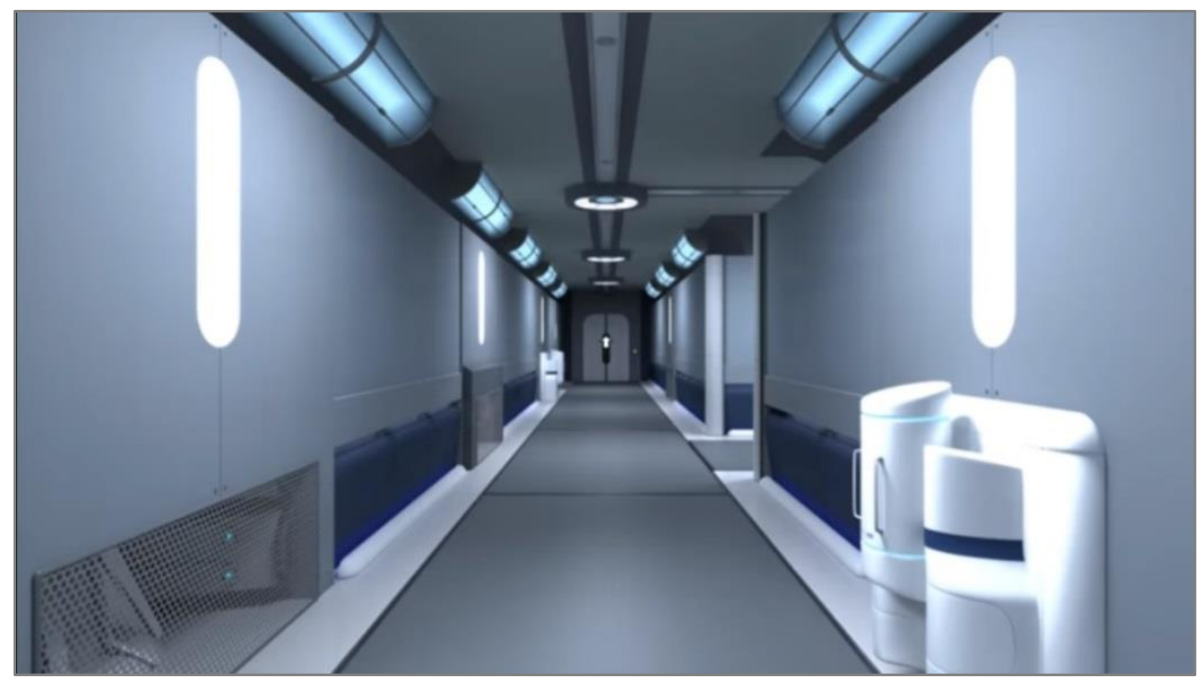

\section{Figure 5: In-Game Footage of The Transition of Virtual Rooms to Enter into Another Room in The Spaceship}

Apart from that, the frame story of "Prominence" is diegetic, which creates the purpose to describe the relations among the plurality of narrating cases within a narrative (Coste \& Pier, 2011, para. 1). It is called diegetic because of the telling of a story by interactor who summarizes events in the plot and comments on the conversations, thoughts, and of the characters. The virtual world of "Prominence" may be linked in certain ways to create a real situation in the sense of logical acceptance, as well as to allow the interactivity progress runs smoothly for interactor. Furthermore, the interactor typically types what the player character is planning to do, who exist within the virtual world. Interactor would generate new ideas or strategies while interacting because of different circumstances they face in the virtual reality world. Thus, this kind of world is not merely the real setting of the recognized real-life world, but this virtual world also serves to force and describe the operation of the narrativegenerating program.

Besides, "Prominence" is the sphere in which these narrated events and other elements occur while interactor engages and interacts with the play. In addition, Montfort also viewed that there is one characteristic of an interactive fiction work that qualifies "Prominence" to be called "simulation of world" which is traversal. In general, the term traversal means "crossing" (Montfort, 2003, 32). Literally, traversal refers to a progress encompassing from a preface to a final reply, and from an opening situation to a final situation. Henceforth, as "Prominence" to be considered a complete interactive fiction, it should have a successful traversal in which ends with a final situation that corresponds to winning and this traversal is reflected in the simulated environment or world model of "Prominence". 
Therefore, "Prominence" is a simulation of real-life world that is interactive. Because of that, "Prominence" is totally different from the conventional printed works which is the representation of real situations in a chronology. In other words, "Prominence" is not a representation but a reflection of real-life events and situations. Based on the three dimensional world of "Prominence" built by Morrison and his team, the interactor who interacts with the play is actually believed that they are having a real battle of survival to escape the abandoned place. Projecting a reflection of real world in "Prominence" is essential to make the interactor feel amused with the scene, colour scheme, sound effects, as well as the mission. As a result, they would not care much about their surroundings and continuously focus on the world they have been only. This part also contributes to the interactor's experience of immersive pleasure in the play since the interactor becomes unconscious with the reality outside the virtual world.

\section{Potential Narrative}

Thirdly, "Prominence" is also a potential narrative, that is, a system which produces narrative during interaction between the interactor and the play. This third element is importantly pointed out to allow "Prominence" to be considered as a kind of interactive fiction. As a form of new media, it allows for the discovery of new texts upon replay with different explorations. "Prominence" has the potential to produce narratives; where in most common cases are resulted from the interactor's act of typing words that effect interactivity in the interactive fiction world. Besides, "Prominence" has a variety of signs and symbols that work as a short cut to obtain new information as well as directly generating a new narrative to relate the previous narrative with the new one, since the option to shape the journey lies upon the interactor's hands. Such signs and symbols that are found in "Prominence" constantly includes 'eye' for observing or obtaining information, 'arrow' for direction, and 'hand' for touching.

To have a potential narrative, "Prominence" should have a system in which the interactor and the one the interactor interact with, in this case, the player's character. Besides that, a part of the system is the puzzle. For the puzzle in "Prominence", there are several kinds of puzzles created such as dynamic but challenging mix of traditional inventory puzzles, graphical interface puzzles, keyboard-based hacking puzzles, as well as environmental puzzles, and they all tied directly to the narratives, which lead to another big part of "Prominence", the character. Many of the characters in "Prominence" have their own arcs that are unfolding alongside the main stories. They will see and hear different perspectives on the plot from different characters as the play progresses. There are about 30 characters in "Prominence" have speaking rules. Over the course of the play, the interactor would uncover emails, voicemails, and sometimes even the entire conversation that played out between multiple characters in believable ways that are connected directly to the story.

The most important part of potential narratives is, the interactor interacts with A.N.N.I.E, a highly advanced computer artificial intelligence (AI). A.N.N.I.E basically stands for "Advanced Neural Network Information Entity" and as an entity; she cannot be seen on the monitor. She is invisible and the interactor interacts with her through her voice that interactor hears. She is another evolving character and her voice and personality transform into valid as a result of interactor's action. Interactor has unintentionally reactivated her online in the Central Computer Control Room. Gradually and without realizing, the interactor transports his self into A.N.N.I.E and share the same experience, information and feeling as her throughout the journey. The interactor will experience "Prominence" differently. By having a "voice" for the protagonist, the play would be locking the interactor into one single version of 
that experience. The play hopes that the interactor will react to the events of the game and be the voice of the protagonist.

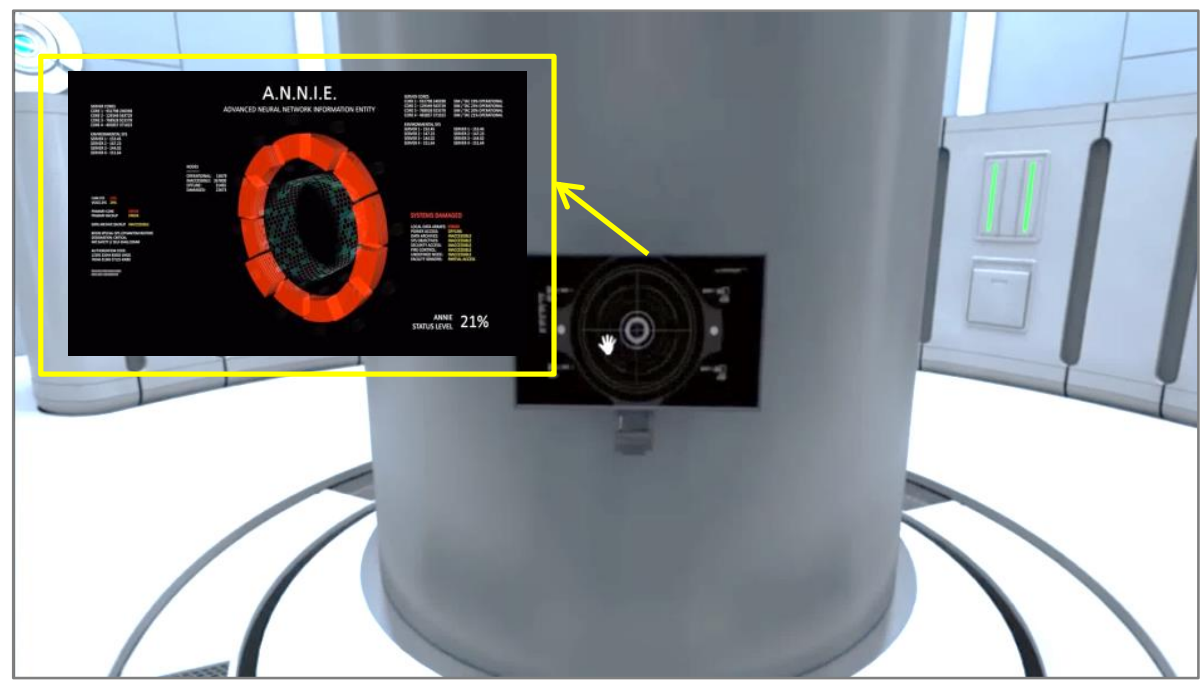

\section{Figure 6: In-game Footage of the Location of A.N.N.I.E in the Central Computer Control Room}

As illustrated in Figure 6, even has been located passively in the Central Computer Control Room, A.N.N.I.E moves very quick in the speed of light. She moves through the digital waves. There are a kind of communication like dialogues occurred between the interactor and the player's character, A.N.N.I.E during interactivity which could be regarded as a part of potential narratives in the play. Such dialogues could lead to a puzzle in the state of mind of the interactor; the interactor tends to have a discussion with A.N.N.I.E and with her special abilities in controlling the spaceship's computer system, A.N.N.I.E and the interactor try to find solution for each problem occurred. Before that, in order to help the mission succeed, A.N.N.I.E needs to be fully functional, as she is only operating at only $21 \%$ capacity when interactor found her. Further, the interactor has to reconnect her to Data Archives which is one of the sub-mission that the interactor needs to complete in order to escape the puzzling barrier with the help of A.N.N.I.E.

Whilst "Prominence" provides short but complex narratives for each challenge, the interactor would find difficulties to interpret the meanings. To some extent, the interactor would end up going back and forth in the same room in order to escape himself and enter a new room. So as the interactor intends to find the ultimate pleasure, the interactor begins to put himself into the player character's shoes and tries to think like the character. As well, the interactor starts to accept the way the player character engaged with the environment and tag along together with her to confront every difficulty in the mission. This is the part where the interactor starts to engage in the play intensely and built a strong connection with the player character. At this part of interactivity, the interactor has gradually become engrossed in the mission and been immersed in the virtual environment he encountered.

Since "Prominence" is a new kind of storytelling in electronic literature, the element of potential narratives in "Prominence" is essential to consider the play as interactive fiction. Potential narrative explains how the story is being told by using computer and other digital devices as the platform. Comparatively to the situation of printed works, narrative is often passive and not expanding in nature. In contrary, narrative in "Prominence" is more alive and growing upon interactor's interactivity with the play. The presence of narratives in 
"Prominence" is interesting because; as the interactor falls deep in the storytelling, he would be immersed in the play as well. The story is not "ready-made" by the play but it is actually developing as a result from the major influences by the interactor's and the player character's interactions. Thus, "Prominence" has a high potential to produce narratives which is one of the important elements of interactive fiction.

\section{Game}

Fourthly, "Prominence" is an interactive fiction and despite its nature as an interactive fiction, it is also identified as a part of game, meaning that it should have these four gameness elements of; a specific system, artificial conflicts, particular rules and certain outcomes, which must be followed by interactors. Montfort coined on Aarseth (2001) and Zimmerman (2001) by stating that this kind of work is considered game if it involves activity based on rules and is interacted for an outcome in term of rewards (Montfort, 2003, 13).

The first element is game as a system. Chris Crawford claimed that "a game is a closed formal system that subjectively represents a subset of reality" (Crawford, 1982, 7). The term "closed' means that "Prominence" is complete and self-sufficient as a structure. The term 'system' is often misused as only the program itself, but in this case its application is quite fitting. A system is referred to the play's components and parts which often interact with each other in complex ways. Further, the phrase 'subjectively represents' refers to representation that is the play represents something from subjective reality, not objective. Fantasy thus plays a vital role in any play situation. "Prominence" creates a fantasy representation, not a scientific model. The last phrase of 'subset of reality' means easily justified. Clearly, no play could include all kinds of reality without being reality itself; thus, "Prominence" must be at the greatest state of subset of reality. The play that represents too large a subset of reality defies the interactor's intellectual capacity and becomes almost indistinguishable from life itself, stealing the play most appealing factor, which is its focus. "Prominence" should afford a level of meaningful interaction within its system to the interactor. This is what makes an interactive fiction like "Prominence" playable and interactive.

At this level, it is sensible to refer to "Prominence" as system. Indeed, system can be seen as sets of items that can affect one another. The interaction among these sets of items can form patterns that are distinctive from its individual parts. Regarding to Littlejohn and Foss, the four essential system elements are as following; objects, attributes, internal relationships, and environment (Salen \& Zimmerman, 2003, 51). By chance, "Prominence" has all these four elements. Because of the nature of these elements is interrelated, "Prominence" is framed as a system, which is a combination of things or parts that form a complex whole. Concisely, objects refer to the elements of a system which could be physical or abstract in nature. For instances, "Prominence" can contain physical objects such as collected items in the inventory and also abstract object like the central computer, A.N.N.I.E.

Whilst attributes are the qualities that a system and the objects within the system could have possessed. Meanwhile, internal relationships are described as the objects in a system are usually in an internal relationship to one another. As examples, "Prominence" can have attributes as well as internal relationships between the interactor and the player's character as in A.N.N.I.E.'s personality where she is extremely helpful and honest while dealing with the interactor in order to complete the mission. Last of all, the element of environment is referred to the system that is influenced by the situation which surrounds them. As an example to the situation, "Prominence" also contains a good vibe of environment which is illustrated in a 
virtual world of Vanguard spaceship system that is similar to the real space life environment NASA people live in.

The second element of a game is artificial conflict. Conflict is referred to the playfulness aspect that lies at the heart of the play. Siitonen (2009) refers conflict to as something that turns a simple challenge into something much more engaging (Quiring, 2015). For instances such as being able to climb up a high ladder into something more difficult like unlocking a malfunctioned door. According to Frans Mayra, there are two main viewpoints into conflict; the conflict between the interactor and the play, and the conflict between interactors (Mayra, 2008, 20). Further, the artificial conflict is then divided into two variants which are intentional and unintentional conflicts. Basically, artificial conflict that is intentional is designed to occur; meanwhile unintentional conflict arises naturally as a part of social interaction to the interactor and the play. However, based on "Prominence" as a single-player play, the artificial conflict is only focused on the conflict between the interactor and the play, and this includes intentional artificial conflict designed by Morrison and his team into the play. As an addition to that, this also includes instances where the needs and motivations of the interactor are in association to the play, in which causing an unexpected and unwanted conflict.

Practically, designing artificial conflict is usually essential to game design. As Crawford (2003) states that conflict liven up challenges. Thus, without conflict, challenge is lifeless and inactive (Wolf \& Perron, 2014, 56). In addition, conflict would appear after the presence of purposeful opponents. Regarding to Wolf and Perron (2014), there are several ways of designing conflicts between interactor and the play. On the concrete level, interactor-versusplay conflicts can be marked as a struggle with enemy non-player characters, the environment of the play, or other potential factors. The key is that of controlling and restricting the actions of the interactor. Indeed, it is important to recall that conflicts are defined by rules, and that interacting by these rules should let the interactor to reach for a meaningful outcome or result (Salen \& Zimmerman, 2004, 80). Typically, when the interactor enters a game, they want to understand it, and ultimately be able to control it. In most cases, the interactor's final goal is to either solve the conflict or find a balance to an unbalanced situation. If the play is found extremely difficult to understand or impossible to control, thus the inner conflict or tension may remain unsolved. On the other hand, if the play is too simple to master, there is hardly conflict or tension could appear from the interaction. Therefore, this part steps into the zone of interactor's aesthetic experience that is subjective and highly varied in phenomenon. Thus, "Prominence" at its best is both a rewarding interacting experience and a challenging game. 


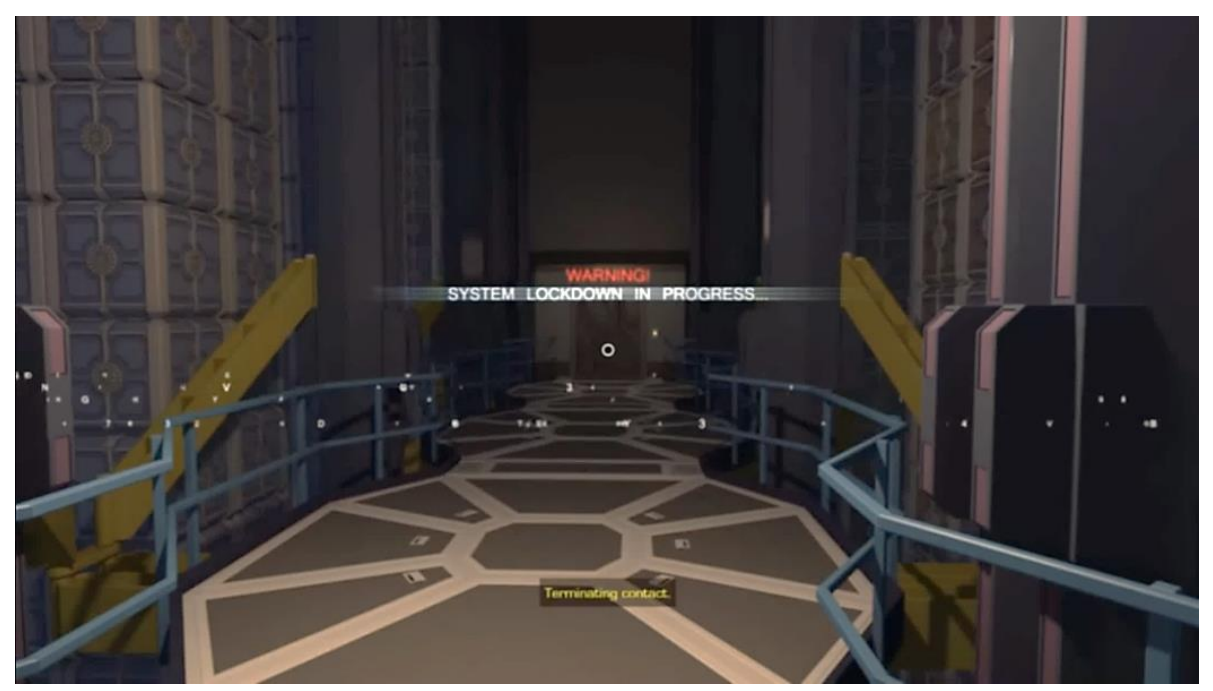

Figure 7: A Screen Shot of the Scene where Artificial Conflict Occurred and has Resulted A.N.N.I.E to Terminate Contact with the Interactor

As notice in Figure 7, the biggest artificial conflict is occurred in the Power Control Room when A.N.N.I.E found out that the individual who is actually stole the seismic charges is the interactor's own self. This is the part when A.N.N.I.E lost her trust to interactor. The nature of A.N.N.I.E as a loyal personality brings her to terminate the communication before anything could harm her. But that does not takes longer time as she is back online after she realizes the exact situation that interactor is being sabotaged by the overrode system. Thus, the interaction between them continues to progress in order to finish the task. That is why Montfort concludes that; by finding a solution in the play does not always require the interactor to unlock new mission or reveal some larger space but it only unleashes a particular barrier or task. As a result, it becomes more complicated when a novice interacts with the play than it does when an expert begins to interact. Hence, this part of solving problem requires interactor to play with the conflict in their mind in order to find solution. In other words, artificial conflict is a part of game, and game is a part of interactive fiction. Therefore, "Prominence" can be considered as a part of game because its gameness characteristics that contents artificial conflict in order to solve a problem during interaction with the play.

The fact that interactor challenges their self to overcome the solution every time problems appear, is due to the state of either 'winning' or 'losing' the task. Most cases in "Prominence" showed that interactor is very passionate to win every challenge so that they could precede the journey to the very end in order to achieve the ultimate goal of winning. Despite intentional conflict that is designed to occur during interactions, there is also unintended conflict that arises naturally while the interactor interacts with the play. There are few causes of unintentional conflict between the interactor and the play to arise; a mismatch between expectations and reality, unsatisfied expectations, and significant conflict potential. Firstly, unintentional conflict can be caused by a mismatch between expectations and reality. This is a conflict of interest where interactor approaches the play thinking that it is a safe and easygoing play, but is provoked by the play being too hard or harsh. Secondly, unintentional conflict can be caused by unsatisfied expectations. This means that the interactor maybe in control of a superhuman character with incredible quickness and strength, but still be unable to open over a malfunctioned door that marks the end of mission in the play.

Thirdly, there is also significant conflict potential in unexpected player behaviour. This part shows that how the interactor could be truly independent and creative in 'reading' the play. 
For instances, the interactor can and will break the rules available in the play, disrupting the system he has embedded in, and causing conflicts to emerge between him and the play that were not intended by the design of the original play. At this part, the interactor has to very confident in deciding the pathways as well as handling the problems encountered. In fact, conflict is an intrinsic element of all games. It can be direct or indirect, violent or nonviolent, but it is always presented in every game. Therefore, the unintended conflicts should actually be expected and comprised, as a proof of the strength of the play and the interactor.

The third element of a game is rules. David Parlett (1999) claimed that "every game is its rules, for they are what define it". The rules are what guide the interactor through the game. It tells them what they can and cannot do in order to win. They not only describe how to play the play, but the rules also help shape the experience. Basically, there are three categories of rules; setup, progression of play, and resolution. Setup refers to things you do at the beginning of the game, progression of play is what happens during the play, and resolution describes what circumstances have caused the play to end, and how is an outcome determined based on the game state. Rules are sometimes automatic, in which they are activated at a certain point in the play without the interactor's choices or interactivity. Meanwhile, other rules define the actions that the interactor can take in the play, as well as the effects of those actions on the play condition. A more conventional definition from Clark C. Abt (2002) stated that the content of a game is its rules in which developed to win the objectives (Michael \& Chen, 2005). For instances in "Prominence", the interactor needs to accomplish each mission setting up in each session. They would use various alternatives to complete the task for example to find the power supply and switch it on. If interactor manages to do so, they win the objective, but if not, they need to figure out the solutions until they succeed.

Some of the characteristics of game rules are known as following; rules limit the interactor's action, rules are explicit and unambiguous, rules are sometimes shared by all interactors, rules are fixed, rules are binding, and rules are repeatable. In their book Rules of Play, Salen and Zimmerman (2003) classify three types of rules, which are operational, constitutive, and implied. As illustrated in Figure 8, "Prominence" is governed under the operational rules. Operational rules are discussed as they describe precisely how an interactor manipulates and interpret objects in the play, as well as describing specific actions that interactor takes. These are the rules that the interactor uses to understand what the play is about. That is why Vanguard is designed dynamically with different elevations of 4 floors vertically and horizontally in repetition. This is because the interactor needs to manipulate objects that they find, interpret particular missions in the play, and also choose specific actions that interactor need to take for each task. Rules are the exact objects and concepts of your game; they are the building blocks of the game system. Rules specify everything the interactor 'can' and 'cannot' do. This means that the interactor often has to limit the actions the interactor is allowed to do and the interactor has to think about reactions of the play to the interactor's actions. 


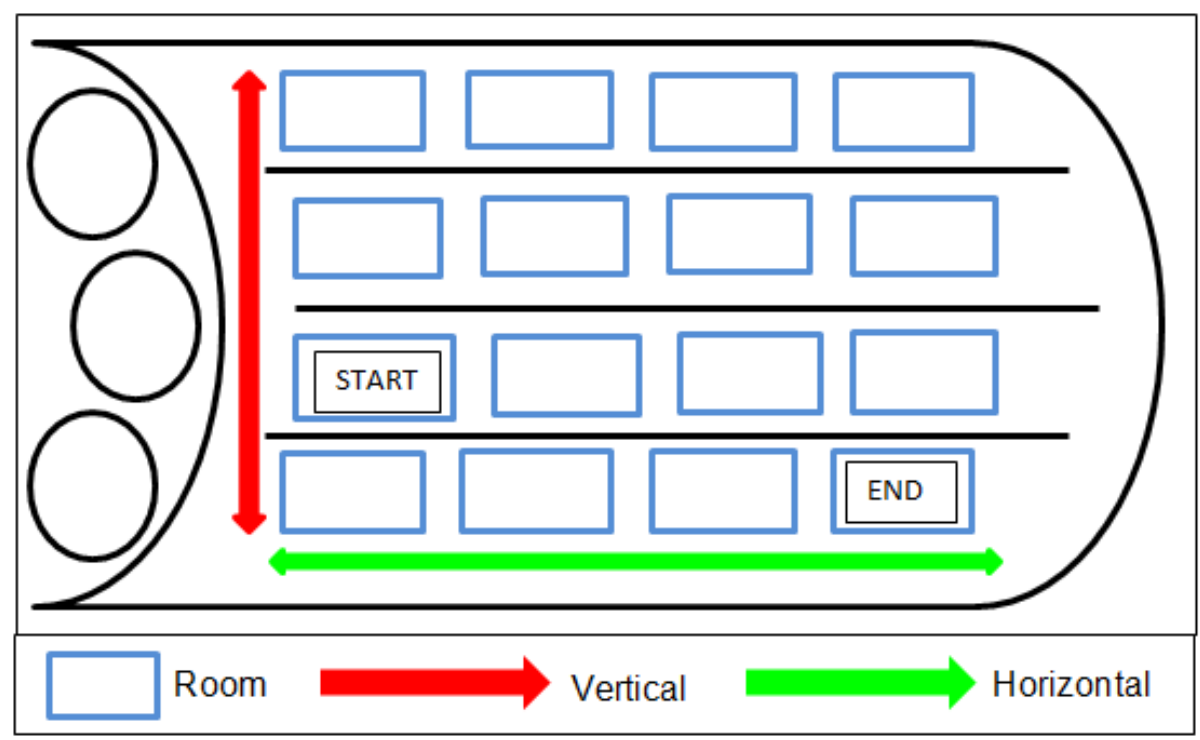

Figure 8: The Model of Vanguard Ship and the Flows of the Interactor's Movement in the Spaceship

As illustrated above, the interactor has to explore all four floors by either going in a horizontal order or a vertical order to find the escapee. But, this does not mean that the interactor needs to follow the rules straightforwardly. Sometimes, the interactor must break some rules in order to escape the locked room. For instance, suppose that interactor always starts at the second floor (the medi-scan laboratory). Here, the artificial conflict is intended by the play and developer. Thus, instead of going vertically to the next floor, the interactor has to go downstairs to the first floor (basement) in order to switch on the power supply so that the selected door is unlocked and the lift is functioning as well. Here, the interactor is already broke the rule to actually go upstairs in a vertical order and prioritized the need of power supply first. Without realizing, the interactor has eventually shaped his own journey from the very beginning of the play.

The last element of game is outcome. The outcome of a game has to be uncertain to foster the interactor's interest. In most games, the outcome is often measurable for example in score of points, and sometimes uneven for instance in one team or one person that has to win. Winning conditions are different from interactor's objectives. Since interactor have invested much time and emotion into a play, it is hard to create a resolution that satisfies this investment of interactor. Besides, game has one or more outcomes, and in most cases it has more than one outcome. For instances, someone wins, and someone loses. In "Prominence", the outcomes appear every time interactor manages to complete the objectives for each submission. As an example, when interactor need to switch all lights on and activate the monitors and touch screens, interactor needs to pass certain barriers in form of locked doors in order to find the main power supply, then after interactor succeeds in doing so, the play would notice the interactor that they had accomplished the objective. As an outcome, interactor would be brought into another phase of new challenge.

The outcome depends on the strategies chosen by interactor, which is called strategic interaction. Strategic interaction means that interactor wish to coordinate their actions but have conflicting interests in the play. Because outcomes in the play are jointly determined, interactor's action is depended not only on their own decisions but also on the decisions of other things related. In "Prominence" case, A.N.N.I.E is the helping hand to the interactor. 
For instance in the first ending when they realised the main ship Vanguard cannot operate to fly anymore due to the severe damages caused by debris from the solar prominence, the interactor has managed to rebuild the shuttle ship, to relocate the power supply, to find the missing disc or navigation module, and to complete the puzzles, because of the help of A.N.N.I.E.

Both of them has planned strategically the last mission and divided the work accordingly. So, when the interactor has finished loaded the supplies to the ship, A.N.N.I.E also finished her investigation to locate the navigation module. It made the interactor's job easier to collect the navigation module and replace the broken one in the ship. Finally, the mission has ended successfully. As well, the interactor is assumed to have common knowledge of the rationality of the elements of the play. If the interactor is lacking of knowledge, the interactor might find that the play is harder to complete. In brief, outcomes in turn determine the interactor's payoffs or rewards. As shown in Figure 9 below, the scene shows both the interactor and A.N.N.I.E has succeeded in completing the mission of rebuilding the shuttle ship in the first ending and flied back to New Lettar safely.

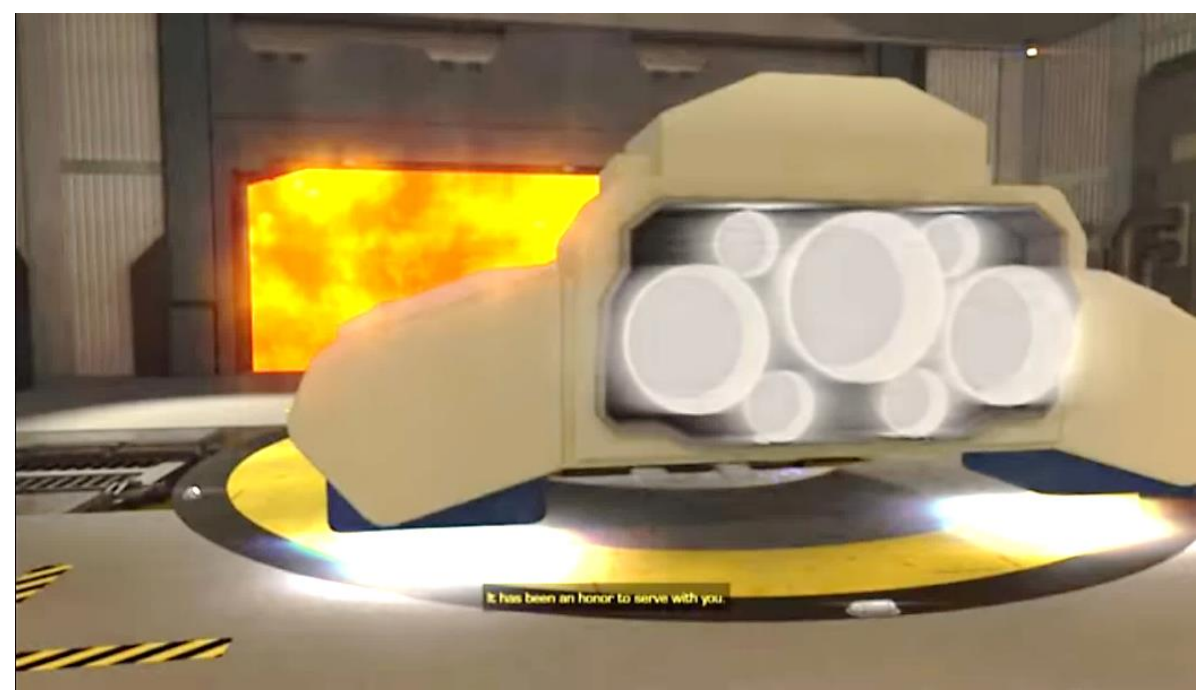

Figure 9: In-game Footage of the First Ending Scene of the Just-rebuilt Shuttle Ship in the Hangar Ready to Fly Back to New Lettar

\section{Conclusion}

In brief, "Prominence" comprehends all of the four prominent elements of interactive fiction; text accepting and text generating computer program, simulation of environment or world, potential narrative, and game. The study believes that the play like "Prominence" which possesses the elements of the structure of interactive fiction can evolve as the developing genre of electronic literature and upraise the interactor's literary understanding. If the interactor's aesthetic experience of the immersive pleasure is understood in the interaction with the play, it is easy to determine which elements and other characteristics of virtual space lend pleasure to the acts of interacting and navigating of new digital genre of fiction. Therefore, this paper hopes to contextualize the elements of the structure of interactive fiction in "Prominence" and deliberate profound discussion on them which is not presented in other kinds of literary works.

\section{References}

Aarseth, E. J. (1997). Cybertext: Perspectives on ergodic literature. Baltimore, US: Johns Hopkins University Press. 
Abt, C.C. (2002). Serious Games. Maryland, US: University Press of America.

Coste, D. \& Pier, J. (2011, August 4). Narrative levels. The living handbook of narratology. Retrieved from http://wikis.sub.uni-hamburg.de/lhn/index.php/Narrative_Levels

Crawford, C. (1982). Century 21 Typewriting. Book 1: Keyboarding Series. $\left(3^{\text {rd }}\right.$ Ed.) US: South-Western Pub. Co.

Crawford, C. (2003). Chris Crawford on Game Design. California, US: New Riders (Pearson Education).

Digital Media Workshop, Inc. (2015). Prominence [PC game]. New York, US: Prominence Game Software.

Mayra, F. (2008). An Introduction to Game Studies: Games in Culture. California, US: SAGE Publications Ltd.

Michael, D. \& Chen, S. (2005). Serious games: Games that educate, train and inform. Boston: Cengage Learning PTR.

Montfort, N. A. (2002). Toward a theory of interactive fiction. In E. Short (Ed.), IF theory, 3. Retrieved from http://nickm.com/if/toward.html

Montfort, N. A. (2005). Twisty little passages: An approach to interactive fiction. Cambridge, MA: The MIT Press.

Parlett, D. (1999). The oxford history of board game. United Kingdom: Oxford University Press.

Plotkin, J. B., \& Kudla, G. (2011). Synonymous but not the same: the causes and consequences of codon bias. Nature Reviews. Genetics, 12 (1), 32-42. http://dx.doi.org/10.1038/nrg2899

Quiring, T. (2015). From voxel vistas: Place-making in Minecraft. Journal for virtual worlds research, 8 (1). doi: http://dx.doi.org/10.4101/jvwr.v8i1.7122

Salen, K. \& Zimmerman, E. (2003). Rules of play: Game design fundamentals. Cambridge, MA: The MIT Press.

Salen, K. \& Zimmerman, E. (2004). Rules of play: Game design fundamentals. Cambridge, MA: The MIT Press.

Siitonen, M. (2009). Conflict management and leadership communication in multiplayer communities. ResearchGate. Retrieved from https://www.researchgate.net/publication/255636974_Conflict_management_and_lea dership_communication_in_multiplayer

Wolf, M. J. P., \& Perron, B. (2014). The Routledge companion to video game studies. New York: Routledge Taylor \& Francis Group.

Zimmerman, B. J. (2001). Theories of self-regulated learning and academic achievement: An overview and analysis. In B. J. Zimmerman \& D. H. Schunk (Eds.), Self-regulated learning and academic achievement: Theoretical perspectives (pp. 1-37). Mahwah, NJ, US: Lawrence Erlbaum Associates Publishers. 